Article

\title{
The Temporal and Spatial Evolution of Water Yield in Dali County
}

\section{Jing Yu ${ }^{1, *}$, Yongwei Yuan ${ }^{1, \dagger}$, Yan Nie ${ }^{2, \dagger}$, Enjun Ma ${ }^{3}$, Hongji $\mathrm{Li}^{1}$ and Xiaoli Geng ${ }^{1}$}

1 Faculty of Resources and Environmental Science, Hubei University, Wuhan 430062, China; E-Mails: yuanyw.simlab@gmail.com (Y.Y.); lihj_dls@163.com (H.L.); gengxl.dls@gmail.com (X.G.)

2 College of Urban \& Environmental Sciences, Central China Normal University, Wuhan 430079, China; E-Mail: nieyan@mail.ccnu.edu.cn

3 School of Mathematics and Physics, China University of Geosciences (Wuhan), Wuhan 430074, China; E-Mail: maej.ccap@igsnrr.ac.cn

$\dagger$ These authors contributed equally to this work.

* Author to whom correspondence should be addressed; E-Mail: yu82jing@gmail.com; Tel.: +86-134-6995-9569.

Academic Editors: Xiangzheng Deng and Ram Babu Singh

Received: 30 November 2014 / Accepted: 22 April 2015 / Published: 18 May 2015

\begin{abstract}
Water yield is of great importance to the balance between supply and demand of water resources. The provision of freshwater for Dali is estimated and mapped in 1988, 1995, 2000, 2005 and 2008, using the Integrated Valuation of Environmental Services and Tradeoffs (InVEST) modeling toolset. The stability of water yield's spatial variation is analyzed by a sorting method. The factors are explored which lead to the change in the relative water yield capacity. The yields at five points in time are compared, and the result of which shows a sharp fluctuation. The water yield curve is of a similar waveform as precipitation. An obvious and relatively stable spatial variation appears for water yield. The highest water yield areas are mainly located in the area where the elevation is high and both the elevation and the slope changes are large, and the main land uses are Shrub Land and High Coverage Grassland. The lowest areas are mainly in the eastern part of Erhai or the surrounding area. Precipitation, construction land expansion and the implementation of policy on land use are the three main factors which contribute to the change of the relative water yield capacity during 1988-2008 in Dali. In the study area, the water yield appears highly sensitive to the change in precipitation. The elasticity coefficient is calculated to
\end{abstract}


illustrate the sensitivity of the water yield to the precipitation. When the elasticity index is larger, the risk of natural disaster will be higher.

Keywords: water yield; spatial variation; relative capacity; sensitivity

\section{Introduction}

Water yield is an ecosystem service [1], which plays a basic role in farming, aquaculture, the processing industry, quality of life for humans and ecological protection. Adequate water production is a premise to sustainable development of the regional economy and society. The change of climate [2] and land cover [3] caused by human activities are major factors leading to changes in water yield. The impact of land cover change is the most direct disturbance from mankind, and it will become increasingly prevalent with the increase in industrialization and urbanization. Since the 1990s, floods and droughts have occurred in China more frequently, and the scope of influence has expanded gradually. The Chinese government has issued a series of policies for land use management and ecological construction to safeguard the sustainable development of the economy and society. Representatives of the policies include Basic Farmland protection system, forest restoration from croplands, grassland restoration from croplands and forests, spatial control of construction land, and low-hill utilization. Discussion on the dynamic change of water yield is conducive to understanding the trends of water supply function in the ecosystem, is beneficial to verify the impact of policy implementation on water supply, and is helpful to develop reasonable and effective programs for ecological construction and water management.

Because the administrative region is usually adopted as a unit in policy implementation and economic activity, in this paper, the administrative boundary replaces the watershed boundary to delineate the scope of the study, which facilitates analyzing the direct impacts of human activities. This is vital as, due to the incomplete watershed, the water yield in this paper characterizes the water production capacity of the ecosystem in the study area, rather than the runoff in the region.

Since the 1970s, many distributed physical hydrological models have been built, such as Soil and Water Assessment Tool (SWAT) [3,4], System Hydrologic European (SHE) [5,6], Netherlands Hydrological Instrument (NHI) [7], Integrated Value Environmental Services Tradeoff (Invest) [2] and so on. Currently, research on hydrologic models pays great attention to simulating the impact of human activities on water resources $[3,4,8]$ and modifying models or calibrating parameters under different environmental conditions [3,9]. In the impact of human activities on water resources, many results showed that land-use changes have brought about changes in surface runoff and groundwater recharge [4]. Hydrologic changes were highly variable both spatially and temporally [2,4]. The freshwater production changes are affected by land cover and topography [4]. Antje Ullrich analyzed the impact of alternative management practices on water quality and quantity. Results showed that the Soil and Water Assessment Tool (SWAT) is very sensitive to applied crop rotations and in some cases even to small variations of management practices. Duration of vegetation and soil cover was most sensitive followed by soil cover characteristics of applied crops [3]. Robert Hoyer considered that water yield estimates were highly sensitive to climate, especially in the lowlands, while nutrient export 
and retention estimates were overwhelmingly driven by land cover [2]. The NHI (Netherlands Hydrological Instrument) consists of various physical models at appropriate temporal and spatial scales for all parts of the water system. It is freely available to hydrologists via an open web interface that enables exchange of all data and tools [7].

Each of the hydrological models has its advantages and disadvantages. The major factors concerning model selection are the accessibility of data and the applicability of the geographical environment conditions. In this paper, we choose the Integrated Value Environmental Services Tradeoff (Invest), which is a tool for ecosystem service assessment to support environmental decision-making, developed in 2007 by Stanford University, the World Wide Fund for Nature and the Nature Conservancy [10]. Because of its ease of operation and data acquisition, the model has been applied to several sites and decision contexts [2,11], and has been introduced and promoted in different watersheds in China [10,12,13].

\section{Overview of Dali County}

Dali County, the capital city of Dali Bai Autonomous Prefecture, is located in the west of Yunnan Province and is situated at $99^{\circ} 58^{\prime}-100^{\circ} 27^{\prime}$ East Longitude and $25^{\circ} 25^{\prime}-25^{\circ} 58^{\prime}$ North Latitude. The topography is complex, and the elevation difference is obvious. It is a typical low-latitude plateau monsoon climate, where there is spring-like weather year around. The annual average temperature is about $15{ }^{\circ} \mathrm{C}$. The annual rainfall is $1056 \mathrm{~mm}$, which is distributed unevenly during the year. Meteorological disasters mainly include drought, floods, frost and so on. Dali is an ethnic minority area that developed earlier than other areas on the southwestern border of China. Meanwhile, the development of the regional economy has been accelerated in recent years; the population density of the dam area around the Erhai basin is more than 310 inhabitants per $\mathrm{km}^{2}$. The antinomy between water supply and demand has become more and more prominent. The location map of the study area is presented in Figure 1.

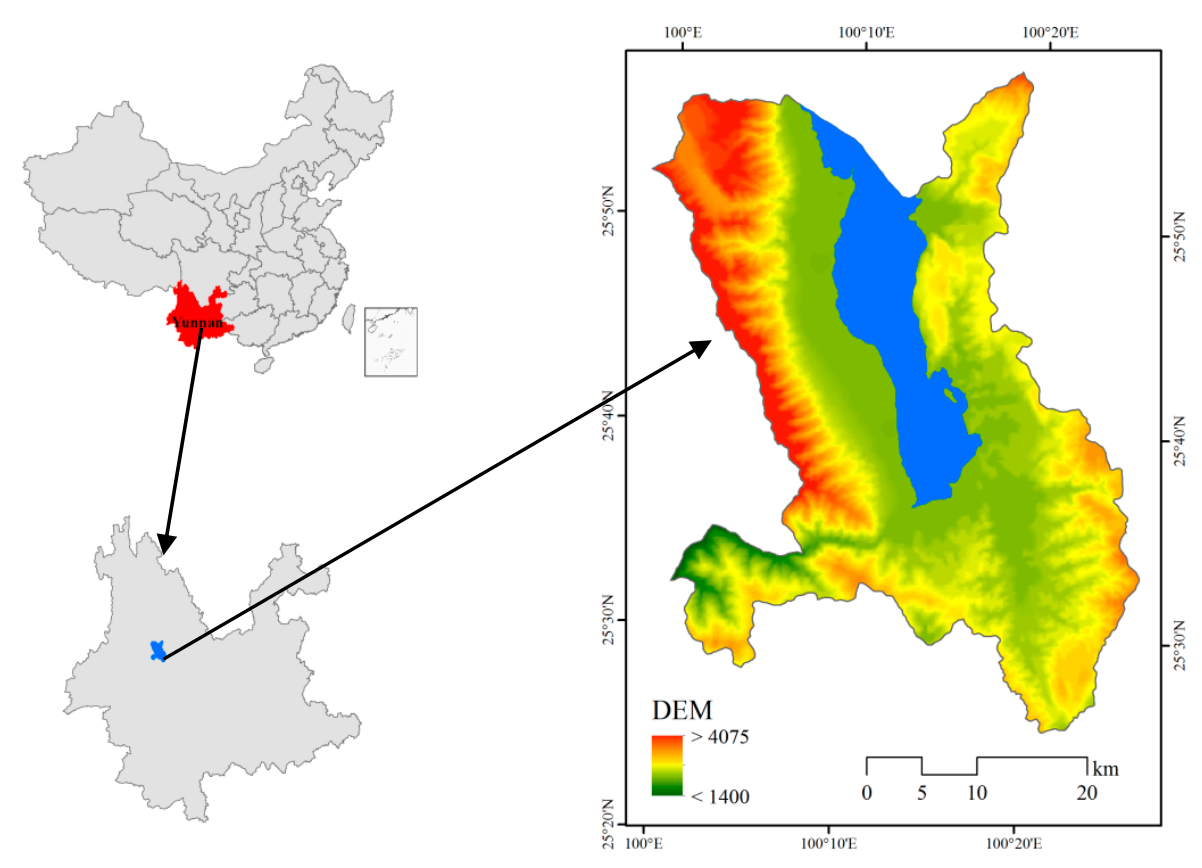

Figure 1. Location map of the study area. 
The dynamic change and spatial pattern of the water yield during 1988-2008 in Dali County was examined. There are several reasons to choose Dali County as the study area. First, the terrain is relatively complex [14]. The topographic gradient layer was extracted from the DEM. The maximum slope of land surface is about $54^{\circ}$. The area whose slope is over $25^{\circ}$ accounted for $13.2 \%$ of the total area. The area whose slope is between $15^{\circ}$ and $25^{\circ}$ accounted for $23.25 \%$ of the total area. These areas have more serious soil erosion, and have a higher frequency of mudslides, landslides or other natural disasters than the more gently-sloped areas. At the same time, the precipitation in rainy season accounted for more than $85 \%$ of the annual precipitation; thus, the spatial variation in water yield and storage capacity have important implications for the occurrence of natural disasters. Second, Dali is not only an area which has high biodiversity and highly sensitive habitats, but is also the capital of the ancient Nanzhao and Dali Kingdom. It is the political, economic and cultural center in ancient Yunnan. Dali is positioned in the Nagorye Basin Ecological Function Zone in Regionalization of Ecological Environmental Function of Yunnan Province. It requires equilibrium of economic development and ecological construction to realize sustainable development [14]. Therefore, this implies that there should be a focus on the impact of human activities on water production and water balance. Moreover, Dali County has attempted to implement the low-hill utilization policy. (Low-hill utilization policy is intended to explore the appropriate land use layout in hilly areas. Under this policy, the low hill area, especially the barren land or wasteland, which is of a certain size and is contiguous, will be explored in accordance with the local conditions. This measure guides people to construct industry and residences in the low hill area. The use of wasteland, defective woodland, or low-grade farmland would survive the hyper-quality farmland in the plain. It is worth noting that, the exploitation may bring ecological and environmental problems when it is excessive or unreasonable). With the promotion of the low-hill utilization policy in China, the evolution of the ecological functions of Dali County will provide a benchmark for more and more areas, especially mountain towns in China.

\section{Model and Data}

\subsection{Water Yield Model}

The water yield in Dali County is calculated based on InVEST modeling. In this model, the Budyko curve is adopted [15].

$$
\begin{gathered}
\mathrm{Y}(\mathrm{x})=\left(1-\frac{\operatorname{AET}(\mathrm{x})}{P(\mathrm{x})}\right) \cdot P(\mathrm{x}) \\
\frac{\operatorname{AET}(x)}{\mathrm{P}(x)}=1+\frac{\operatorname{PET}(x)}{\mathrm{P}(x)}-\left[1+\left(\frac{\operatorname{PET}(x)}{\mathrm{P}(x)}\right)^{w}\right]^{1 / w}
\end{gathered}
$$

where, $\mathrm{Y}(\mathrm{x})$ is the water yield, $\operatorname{AET}(\mathrm{x})$ is the annual actual evapotranspiration for pixel $\mathrm{x}, \mathrm{P}(\mathrm{x})$ is the annual precipitation on pixel $\mathrm{x}, \operatorname{PET}(x)$ is the potential evapotranspiration and $w$ is a parameter that characterizes the natural climatic-soil properties.

$$
\operatorname{PET}(x)=\mathrm{K}_{\mathrm{c}}\left(\ell_{x}\right) \cdot \mathrm{ET}_{0}(x)
$$

where, $\operatorname{ET}_{0}(x)$ is the reference evapotranspiration for pixel $\mathrm{x}$ and $\mathrm{K}_{\mathrm{c}}\left(\ell_{x}\right)$ is the vegetation evapotranspiration coefficient. 
$\mathrm{ET}_{0}(x)$ reflects local climatic conditions. In this study, the FAO-56 PENMAN-MONTEITH EQUATION was employed as the method which provides consistent $\mathrm{ET}_{0}$ values in all regions and climates [16]. The FAO-56 PENMAN-MONTEITH EQUATION is given as

$$
\begin{gathered}
\mathrm{ET}_{0}=\frac{0.408 \Delta\left(\mathrm{R}_{\mathrm{n}}-\mathrm{G}\right)+\gamma \frac{900}{\mathrm{~T}+273} \mathrm{U}_{2}\left(\mathrm{e}_{\mathrm{s}}-\mathrm{e}_{\mathrm{a}}\right)}{\Delta+\gamma\left(1+0.34 \mathrm{U}_{2}\right)} \\
\Delta=\frac{4098\left[0.6108 \exp \left(\frac{17.27 \mathrm{~T}}{\mathrm{~T}+237.3}\right)\right]}{(\mathrm{T}+237.3)^{2}}
\end{gathered}
$$

where, $\mathrm{Rn}$ is the net radiation at the crop surface in $\mathrm{MJ} \mathrm{m}{ }^{-2} \cdot \mathrm{day}^{-1}, \mathrm{G}$ is the soil heat flux density in $\mathrm{MJ} \mathrm{m}^{-2} \cdot \mathrm{day}^{-1}$, $\mathrm{T}$ is the mean daily air temperature at $2 \mathrm{~m}$ height in ${ }^{\circ} \mathrm{C}, \mathrm{U}_{2}$ is the wind speed at $2 \mathrm{~m}$ height in $\mathrm{m} \cdot \mathrm{s}^{-1}$, $\mathrm{e}_{\mathrm{s}}$ is the saturation vapor pressure in $\mathrm{kPa}, \mathrm{e}_{\mathrm{a}}$ actual vapor pressure in $\mathrm{kPa}, \Delta$ is the slope of vapour pressure curve in $\mathrm{kPa} \cdot{ }^{\circ} \mathrm{C}^{-1}$ and $\gamma$ is the psychrometric constant in $\mathrm{kPa} \cdot{ }^{\circ} \mathrm{C}^{-1}$.

$\mathrm{e}_{\mathrm{s}}$ is calculated by Goff-Gratch equation which is recommended by World Meteorological Organization [17].

$$
\begin{gathered}
\operatorname{lge}_{\mathrm{s}}=10.79574\left(1-\frac{273.16}{\mathrm{~T}+273.15}\right)-5.02800 \lg \left(\frac{\mathrm{T}+273.15}{273.16}\right)+1.50475 \\
\times 10^{-4}\left[1-10^{-8.2969\left(\frac{\mathrm{T}+273.15}{273.16}-1\right)}\right]+4.2873 \\
\times 10^{-4}\left[10^{4.76955\left(1-\frac{273.16}{\mathrm{~T}+273.15}\right)}-1\right]+0.7861 \\
\mathrm{e}_{\mathrm{a}}=\mathrm{e}_{\mathrm{s}} \times \mathrm{RH} / 100
\end{gathered}
$$

where, $\mathrm{RH}$ is the relative humidity in $\%$.

\subsection{Data Preparation}

The model requires eight parameter layers/documents, including $\mathrm{ET}_{0}(x), \mathrm{P}(x)$, depth to root restricting, plant available water fraction, land use, watersheds, sub-watershed and biophysical table.

Reference Evapotranspiration Layer and Precipitation Layer. The meteorological data, consisting of mean air temperature at $2 \mathrm{~m}$ height, wind speed at $2 \mathrm{~m}$ height, relative humidity and precipitation, are acquired from the China Meteorological Bureau, and are interpolated into the $1 \mathrm{~km} \times 1 \mathrm{~km}$ grid pixel data according to the Kriging algorithm [18,19]. The net radiation at the crop surface is 5706.5 $\mathrm{MJ} \mathrm{m}^{-2}$. day $^{-1}$ [20], $\gamma$ is obtained as 0.54 for Dali from the Psychometric Constant Table in Crop evapotranspiration-Guidelines for computing crop water requirements-FAO Irrigation and drainage paper 56. Other parameters are calculated by Equations (4)-(7) by the grid operator based on ArcGIS. Taking 2008 as an example, the Reference Evapotranspiration Layer and the Precipitation Layer are presented in Figure 2a,b.

Depth to Root Restricting Layer and Plant Available Water Fraction Layer. Root restricting layer depth is not available in Dali, thus we take reference soil depth as a proxy [15]. Plant available water content (PAWC) is defined as the difference between the fraction of volumetric field capacity and permanent wilting point. It can be estimated based on physical and chemical properties of soil $[10,15]$. 
The physical and chemical properties of soil, including the proportion of sand, silt, clay and the reference soil depth, are acquired from Harmonized World Soil Database [21]. PAWC is generated by the Soil-Plant-Atmosphere-Water (SPAW) software and ArcGIS. Taking 2008 as an example, the Depth to Root Restricting Layer and the Plant Available Water Fraction Layer are presented in Figure 2c,d.

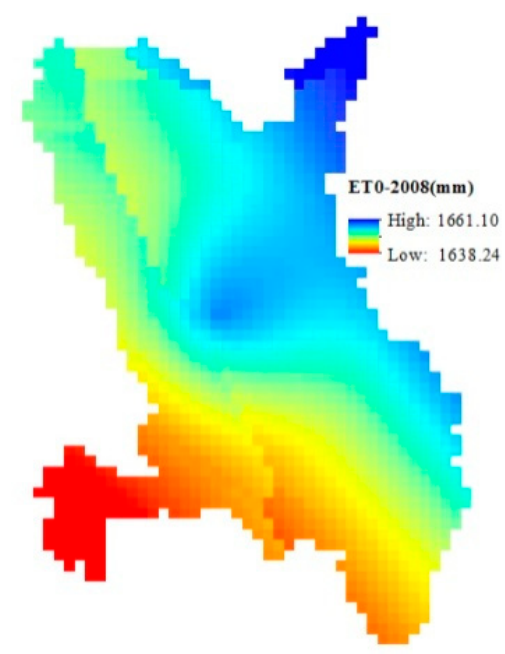

(a)

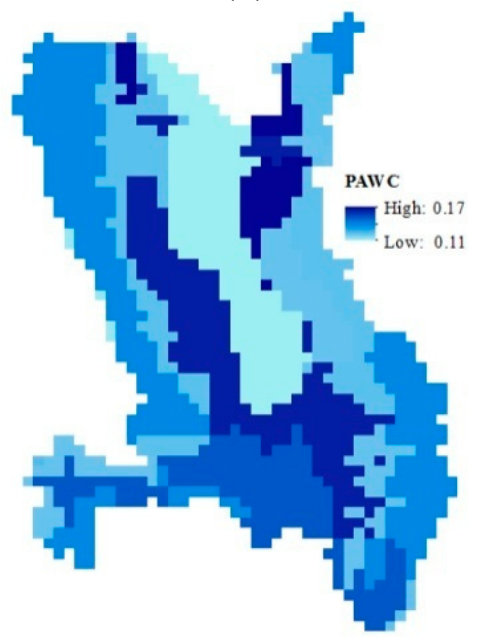

(d)

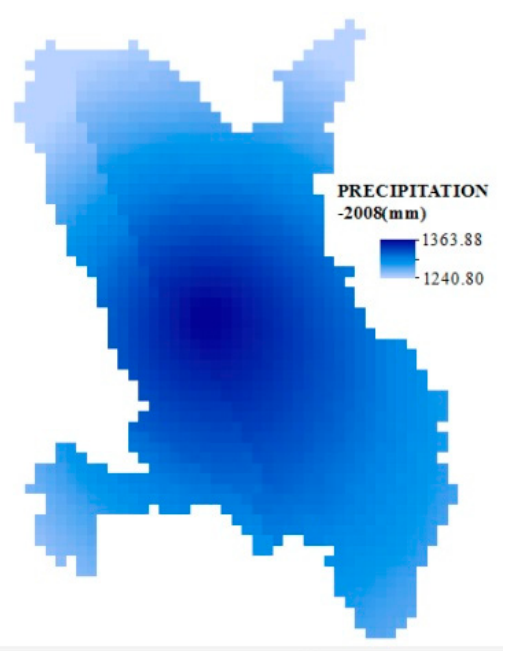

(b)

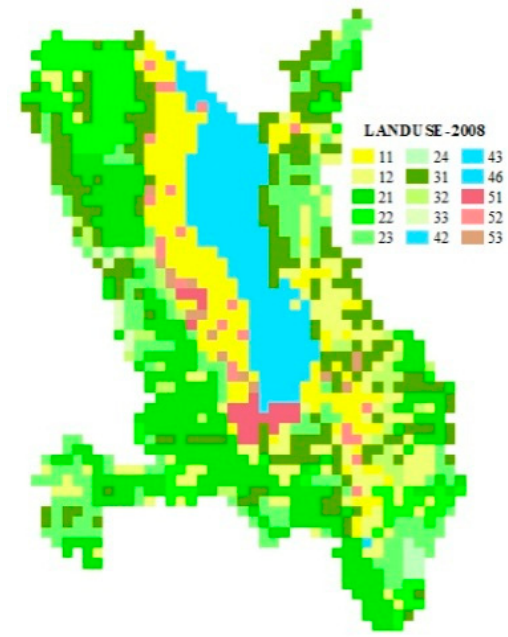

(e)

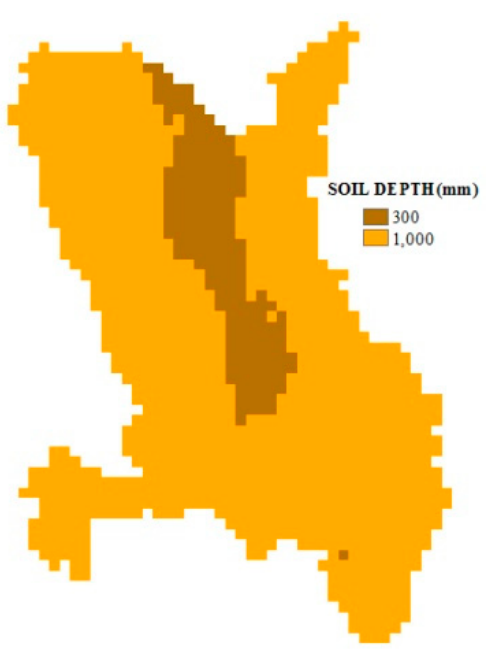

(c)

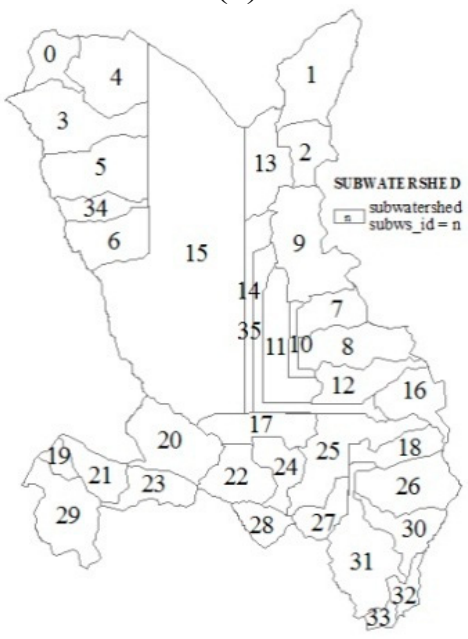

(f)

Figure 2. Layers obtained in data preparation, taking 2008 as an example. (a) Reference evapotranspiration layer; (b) Precipitation layer; (c) Depth to root restricting layer; (d) Plant available water fraction layer; (e) Land use layer; (f) Sub-watersheds.

Land Use Layer. Land use data is derived from the Data Center of the Chinese Academy of Sciences, which is composed of 25 kinds of land use categories. Landsite TM/ETM images were interpreted at a scale of 1:100,000 and the overall interpretation accuracy of the land use categories reached $92.7 \%$ by field survey and random sampling check conducted by the Data Center of the Chinese Academy of Sciences (CAS) [18,22]. In this study, Dali land use covers 15 kinds of landuse categories, including Paddy Field (11), Dry Land (12), Forest Land (21), Shrub Land (22), Wood Land (23), Other Wood Land (24), High Coverage Grassland (31), Mid Coverage Grassland (32), Low Coverage Grassland (33), Lakes (42), Reservoir Pond (43), Beaches (46), Urban Land (51), Rural 
Settlements (52) and Other Construction Land (53). The estimated areas of land use in Dali County are shown in Table 1, and the land use layer in 2008 is presented in Figure 2e.

Table 1. Remotely-sensed estimated areas of land use in Dali County $\left(\mathrm{km}^{2}\right)$.

\begin{tabular}{cccccc}
\hline Land Use Code & $\mathbf{1 9 8 8}$ & $\mathbf{1 9 9 5}$ & $\mathbf{2 0 0 0}$ & $\mathbf{2 0 0 5}$ & $\mathbf{2 0 0 8}$ \\
\hline 11 & 196 & 192 & 185 & 185 & 173 \\
12 & 147 & 117 & 149 & 147 & 138 \\
21 & 262 & 234 & 263 & 240 & 260 \\
22 & 127 & 149 & 132 & 142 & 128 \\
23 & 184 & 195 & 182 & 178 & 186 \\
24 & 0 & 0 & 0 & 0 & 7 \\
31 & 238 & 258 & 231 & 238 & 233 \\
32 & 38 & 33 & 38 & 33 & 36 \\
33 & 8 & 1 & 8 & 1 & 8 \\
42 & 180 & 198 & 180 & 198 & 180 \\
43 & 1 & 1 & 1 & 1 & 1 \\
46 & 2 & 2 & 2 & 2 & 2 \\
51 & 8 & 14 & 19 & 22 & 24 \\
52 & 21 & 20 & 22 & 22 & 23 \\
53 & 2 & 0 & 2 & 5 & 15 \\
\hline
\end{tabular}

Watersheds and Sub-watersheds. Based on the digital elevation model (DEM), the watersheds and sub-watersheds are generated using ArcGIS. Each watershed and sub-watershed is given a unique identification number which is named as ws_id and subws_id. There are six watersheds and 36 sub-watersheds in Dali. The sub-watersheds layer in 2008 is presented in Figure $2 \mathrm{f}$.

Biophysical table. Below is a table of land use classes, containing data on biophysical coefficients. These data are attributes of each land use class rather than attributes of individual cells in the raster map. According to Dali land cover condition, parameters are determined with reference to FAO Irrigation and drainage paper 56 [16] as shown in Table 2.

Table 2. Biophysical details for Dali.

\begin{tabular}{ccccc}
\hline Land Use Description & Land Use Code & Kc & Root Depth $(\mathbf{m m})$ & Land Use Vegetation \\
\hline Paddy Field & 11 & 0.65 & 2100 & 1 \\
Dry Land & 12 & 0.65 & 2100 & 1 \\
Forest Land & 21 & 1 & 5200 & 1 \\
Shrub Land & 22 & 0.398 & 5200 & 1 \\
Wood Land & 23 & 1 & 5200 & 1 \\
Other Wood Land & 24 & 1 & 5200 & 1 \\
High Coverage Grassland & 31 & 0.65 & 2600 & 1 \\
Mid Coverage Grassland & 32 & 0.65 & 2600 & 1 \\
Low Coverage Grassland & 33 & 0.65 & 2600 & 1 \\
Lakes & 42 & 1.2 & 100 & 0 \\
Reservoir Pond & 43 & 1.2 & 100 & 0 \\
Beaches & 46 & 1.2 & 100 & 0 \\
Urban Land & 51 & 0.3 & 100 & 0 \\
Rural Settlements & 52 & 0.3 & 100 & 0 \\
Other Construction Land & 53 & 0.3 & 100 & 0 \\
\hline
\end{tabular}


Seasonality factor $(Z) . \mathrm{Z}$ is an empirical constant that captures the local precipitation pattern and hydrogeological characteristics, with typical values ranging from 1-20. Following a study by Donohue et al. encompassing a range of climatic conditions in Australia, $\mathrm{Z}$ could be estimated as $0.2 \times \mathrm{N}$, where $\mathrm{N}$ is the number of rain events per year [15]. A rain event is characterized by a minimum period of $6 \mathrm{~h}$ between two storms. Calibration of the $\mathrm{Z}$ coefficient may also be used by comparing modeled and observed data [10]. As a result of incomplete watershed, the data of Dali County on the observed river flow at the watershed outlet is not equal to the water yield. Thus, the $\mathrm{Z}$ value is estimated based on frequency of rainfall in Dali as 7.8.

\section{Result}

\subsection{Dynamic Change of Water Yield in the Whole Study Area}

Based on InVEST model, the weighted mean precipitation per pixel (Precip_mn), the weighted mean potential evapotranspiration per pixel (PET_mn), the weighted mean actual evapotranspiration per pixel (AET_mn), and the weighted mean water yield per pixel (Wyield_mn) in 1988, 1995, 2000, 2005 and 2008 was obtained. The dynamic of water yield and related factors are shown in Figure 3. To illustrate the dynamic change of the water yield in Dali, the water yield is calculated through Wyield_mn.

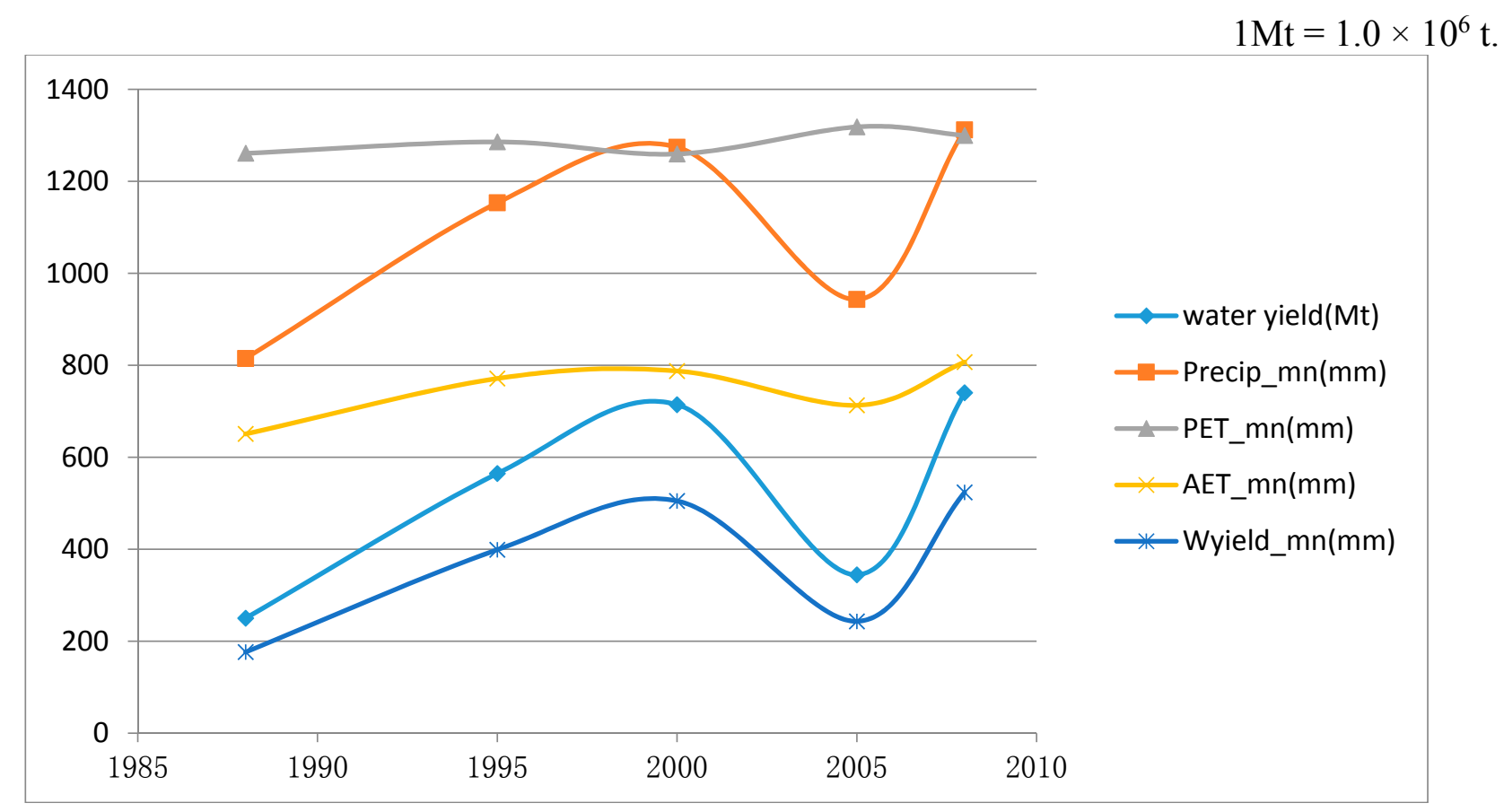

Figure 3. Dynamic of water yield and related factors.

From 1988-2008, water yield in Dali shows a fluctuating trend. The peak of water yield appears in 2008, which is $740.02 \mathrm{Mt}$. The minimum value appears in 1988, which is $249.98 \mathrm{Mt}$. The peak is almost three times the minimum. Taking into consideration the overall water yield and other factors, the volatility of the water yield curve, Precip_mn curve and Wyield_mn curve is very similar. On the surface, it looks like the most important factor affecting water yield is still rainfall, which coincides 
with the results of Robert Hoyer [2] and Li-Chi Chiang [13]. However, between the Precip_mn and Wyield_mn curve, there is no a steady ratio of Wyield_mn and Precip_mn, which fluctuates $20 \% \sim 40 \%$.

PET_mn and AET_mn are influenced by the net radiation, temperature, wind speed, soil characters and land covers [16]. Compared with the precipitation, the above factors, except for land covers, are relatively stable. Construction land is the most obvious region of human interference in the ecosystem. Based on the remotely-sensed estimated data, there is only $31 \mathrm{~km}^{2}$ area which was altered to construction land during 1988-2008. The conversions among other land covers are also lower than 20 $\mathrm{km}^{2}$. In respect to the entire study area, the impact of land cover was not significant either. On the county scale, PET_mn and AET_mn exhibit smaller amplitude.

\subsection{Classification of Sub-Watershed Units}

It is assumed that the water yield of each sub-basin will vary with precipitation, temperature and other factors, but the relative capacity of water yield among sub-watersheds will not change in the absence of interference, because the spatial structure of the geographical environment has had consistent strong stability over time. This assumption is consistent with Robert Hoyer's conclusion on the stability of spatial patterns for provision of freshwater ecosystem services [2]. Based on this assumption, the sub-watershed units are sorted from small to large according to the Wyield_mn in each period, which is used to describe the relative capacity of water yield.

Based on our assumption, we expect larger changes in sort to be linked to stronger human interference. Accordingly, we label the categories "Mild", "Moderate", "Severe" and "Serious Interference Category" except for "Stable Category". The Stable Category includes the units whose range is less than 5, which means the water yield capacity is relatively stable and the fluctuations are due to changes in other units. For this category, the relative capacity of water yield in each unit is depicted by the average of the sorts in the above five time points. While, the units, whose inter-annual change in sort is categorized according to values of $5-10,10-15,15-20$ or over 20 , are put into "Mild", "Moderate", "Severe" and "Serious Interference Category" separately. These changes are considered to be caused by external interference. Due to the instability of these units sort, the focus should be on the extent of interference and the layout of units rather than the average value of sorts in each unit.

For example, the unit whose subws_id is 1 is sorted as 30, 30, 30, 31 and 31, respectively, for five different years as above. The maximum is 31 , and the minimum is 30 , so the inter-annual change is 1 . This unit should be merged in the first category, and its relative capacity for water yield is 30 after rounding. Similarly, the unit whose subws_id is 17 is valued at 22, 28, 27, 28 and 28, respectively. The inter-annual change across values is 6 . This unit should be merged with the mild interference category, and the interference is mainly concentrated in the period between 1988 and 1995.

The classification statistical features are presented in Table 3, and the classification is shown in Figure 4a. In the study area, there are 20 units belonging to the Stable Category, which cover about $50 \%$ of the area. Among the Interference Categories, Mild Interference Category has the largest proportion, which covers $41.8 \%$ of the area. These two categories together accounted for more than $90 \%$ of the area. The units who belong to the Moderate Interference Category are mainly distributed in 
the southeast of Dali, which cover about $8.91 \%$ of the area. There is only one unit belonging to Severe Interference Category and Serious Interference Category separately, and they cover less than $0.5 \%$ of the area. In the following, the spatial variation of the relative capacity of the water yield will be analyzed based on the Stable Category database, and the driving factors of the water yield capacity change will be examined according to local scales based on the Interference Category database.

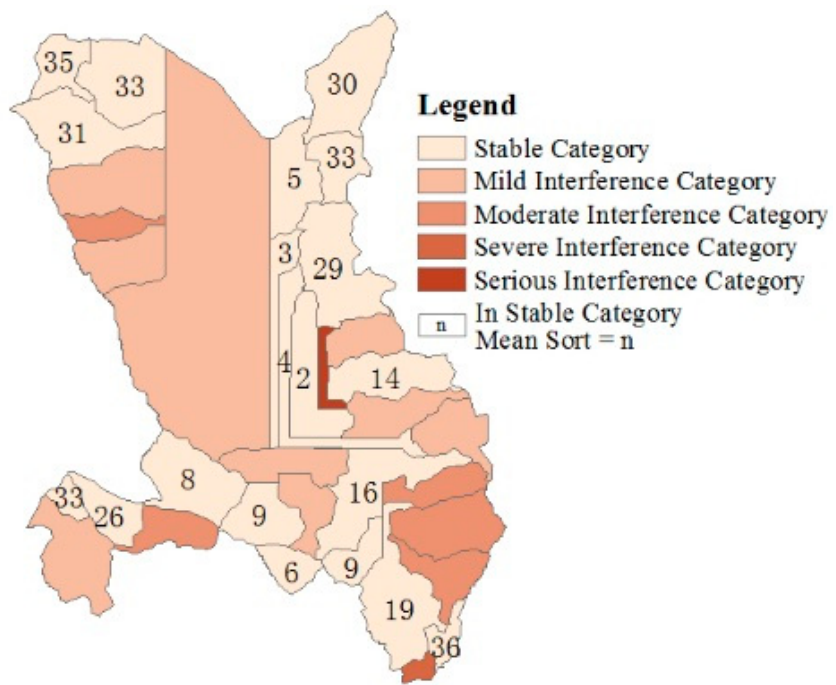

(a)

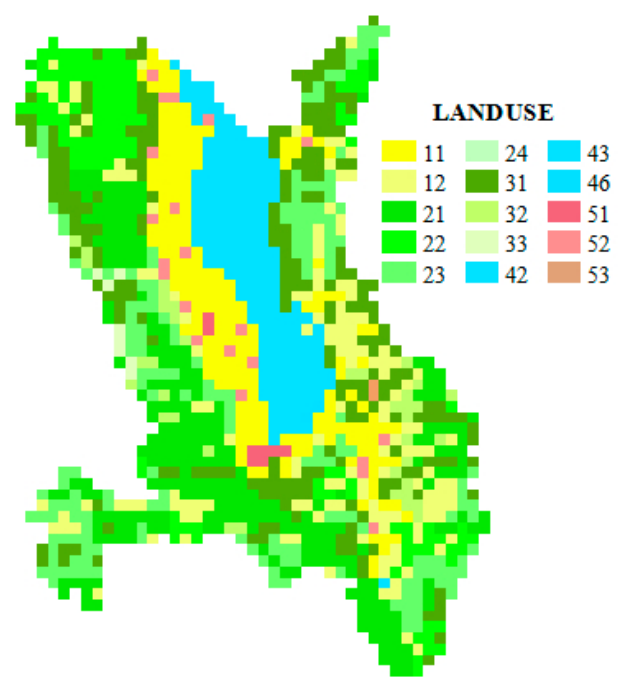

(b)

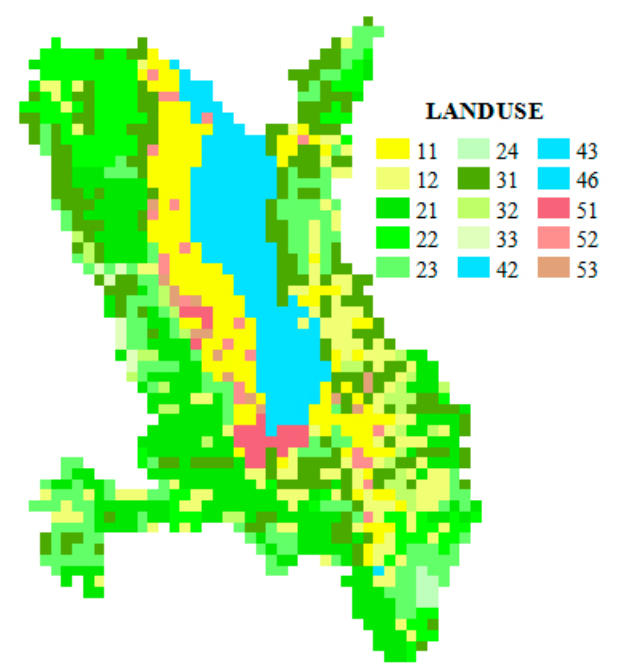

(c)

Figure 4. (a) The classification according to the change of the unit's across five time points; (b) Land Use Layer in 1988; (c) Land Use Layer in 2008.

Table 3. Classification statistical tables according to the change of the sort of each sub-watershed.

\begin{tabular}{cccc}
\hline Category & Number of Sub-Watershed & Area $\left(\mathbf{k m}^{\mathbf{2}}\right)$ & Ratio (\%) \\
\hline Stable Category & 20 & 692 & 48.94 \\
Mild Interference Category & 9 & 591 & 41.8 \\
Moderate Interference Category & 5 & 126 & 8.91 \\
Severe Interference Category & 1 & 4 & 0.28 \\
Serious Interference Category & 1 & 1 & 0.07 \\
\hline Sum & 36 & 1414 & 100 \\
\hline
\end{tabular}




\subsection{Spatial Variation of Water Yield in Sub-Watershed Scale}

The Interference Categories' units are not stable over time, which means the relative capacity of units cannot be delineated. Therefore, the spatial variation of water yield will be analyzed based on the Stable Category database.

In Section 4.2, the sub-watershed units are sorted from small to large according to the Wyield_mn in each period. So, if the sort is larger, the unit's capacity on water yield is larger. Eight sub-watersheds sorted last in the sequence all belong to the Stable Category. They are mainly located in the Northwest and Northeast of Dali. According to the DEM (Figure 1), the elevation in these areas range from $1400-4075 \mathrm{~m}$, and the average is $2705 \mathrm{~m}$. The slope in these areas range from $2^{\circ}-55^{\circ}$, and the average is $13^{\circ}$. The common feature of these units is that they are located in the area where the elevation is high and both the elevation and the slope changes are large. Comparing the land use map in 1988 with 2008 (Figure 4b,c), the land use patterns in these regions are relatively stable. The change only occurred in six pixels which is less than $1 \%$ of Stable Category area. The main land use includes Shrub Land (22), High Coverage Grassland (31), Wood Land (23) and Dry Land (12). Based on the analysis of the precipitation, and the potential evapotranspiration and actual evapotranspiration of these sub-watersheds during five different years as above, the relationship between the parameters' mean level of these regions and the entire area experiences little interannual change. As a result, the data from 2008 is used to illustrate the regular pattern. The annual precipitation of these regions is between $1253.07 \mathrm{~mm}$ and $1323.10 \mathrm{~mm}$, and the average is $1284.61 \mathrm{~mm}$ which is similar to the average level $(1311.85 \mathrm{~mm})$ of the entire area. The difference is only about $2 \%$. While, the annual actual evapotranspiration of these units is between $542.22 \mathrm{~mm}$ and $753.89 \mathrm{~mm}$, and the average is $640.52 \mathrm{~mm}$ which is far below the average level $(799.94 \mathrm{~mm})$ of the entire region. The difference between them balloons to about $25 \%$. Due to the fact that the division of the sub-watershed is not based on land use patterns, there is a variety of land use patterns mixed together in one sub-watershed. At the same time, the land use which appears in these units would also appear in a moderate level or low level water yield sub-watershed. Thus, it does not mean that the area which is used as the above land-use types must be a high water yield area, but it illustrates that these land uses would probably be of benefit to improving the water yield.

Correspondingly, if the unit's sort is smaller, the unit's capacity for water yield is smaller. The sub-watersheds sorted in 2-5 are mainly distributed in the eastern part of Erhai or the surrounding area. The average elevation is $2083 \mathrm{~m}$, and the average slope is $5^{\circ}$. The low level of water yield in these units is largely due to the higher actual evapotranspiration than other regions. It is found that these units are relatively stable, and the relationship between the mean level of these regions and the entire area in regards to precipitation, potential evapotranspiration and actual evapotranspiration has little interannual change. Here, the data of 2008 is also taken as an example to illustrate the regular pattern. The annual precipitation of these regions is between $1307.65 \mathrm{~mm}$ and $1341.72 \mathrm{~mm}$, and the average is $1331.14 \mathrm{~mm}$ which is similar to the average level $(1308.14 \mathrm{~mm})$ of the entire area. The difference is only about $2 \%$. While, the annual actual evapotranspiration of these units is between $981.2 \mathrm{~mm}$ and $1204.65 \mathrm{~mm}$, and the average is $1073.37 \mathrm{~mm}$ which is far above the average level (799.94 mm) of the entire region. The difference between them expands to about $34 \%$. Thus, the water yield, the difference between the precipitation and actual evapotranspiration is the lowest in Erhai. 
The rest of the units which belong to the Stable Category are mainly distributed in the south of Dali. The average elevation is $2292 \mathrm{~m}$. This is $400 \mathrm{~m}$ lower than the high water yield units whose sorts are 29-36 and $200 \mathrm{~m}$ higher than the low water yield units whose sorts are 2-5. With the altitude decreasing, the temperature increases slightly, and the actual evapotranspiration increases gradually.

\subsection{Driven Factors of Relative Capacity Change on Water Yield}

For the Interference Category, the dynamic of each unit's sort is analyzed (Table 4). Results show that there are three patterns in sort changing, namely a decrease, an increase, and a fluctuation.

Table 4. List of the interfered sub-watersheds' values at different intervals.

\begin{tabular}{ccccccccc}
\hline Subws_id & $\mathbf{1 9 8 8}$ & $\mathbf{1 9 9 5}$ & $\mathbf{2 0 0 0}$ & $\mathbf{2 0 0 5}$ & $\mathbf{2 0 0 8}$ & Range & Category & Interval \\
\hline 6 & 15 & 14 & 12 & 9 & 12 & 6 & Mild & a decrease \\
17 & 22 & 28 & 27 & 28 & 28 & 6 & Mild & an increase occurred in 1995 \\
24 & 17 & 17 & 21 & 17 & 24 & 7 & Mild & an increase occurred in 2008 \\
7 & 20 & 24 & 16 & 22 & 20 & 8 & Mild & a fluctuation occurred in 2000 \\
5 & 25 & 21 & 20 & 18 & 16 & 9 & Mild & a decrease \\
12 & 19 & 16 & 23 & 20 & 25 & 9 & Mild & an increase occurred in 2000 \\
15 & 12 & 4 & 7 & 3 & 7 & 9 & Mild & a decrease occurred in 1995 \\
16 & 26 & 19 & 28 & 25 & 27 & 9 & Mild & a fluctuation occurred in 1995 \\
29 & 27 & 22 & 24 & 19 & 18 & 9 & Mild & a decrease \\
18 & 13 & 11 & 19 & 13 & 22 & 11 & Moderate & fluctuated frequently \\
23 & 23 & 18 & 22 & 12 & 21 & 11 & Moderate & fluctuated frequently \\
34 & 18 & 8 & 11 & 7 & 11 & 11 & Moderate & a decrease occurred in 1995 \\
26 & 24 & 13 & 26 & 16 & 26 & 13 & Moderate & fluctuated frequently \\
30 & 10 & 23 & 13 & 23 & 13 & 13 & Moderate & fluctuated frequently \\
33 & 11 & 27 & 15 & 27 & 14 & 16 & Severe & fluctuated frequently \\
10 & 1 & 25 & 1 & 24 & 1 & 24 & Serious & fluctuated frequently \\
\hline
\end{tabular}

For ease of description, the duration of the two adjacent time points in the study is referred to as internal. For a decrease pattern, the number of the decreasing intervals is more than the increasing intervals, which appears in 6, 5, 15, 34 and 29 sub-watersheds (subws_id, the same below). At the same time, if there is an interval whose change is over 5, its change represents a decrease. In unit 6 and 5 , changes in all intervals are less than 5 , but the difference between the minimum and the maximum is greater than 5. Through a careful comparison among the data, there is no difference in land use, soil depth, geological structure and other geographical conditions in unit 6 from 1988-2008. While in unit 5 , whose range is larger, there is about $7.7 \%$ of area that has experienced changes in land use. By inference, the former decrease in sorting is still subject to the change of other regions, but the latter one is caused by relative factors. From this perspective, it is appropriate and rigorous to set 5 as the critical point of the maximum and minimum amplitude when the Stable Category is extracted from the others. An increasing pattern means the number of the increasing intervals is more than the decreasing intervals. Furthermore, if there is an interval whose change is over 5, its change represents an increase. This pattern exists in 17, 24 and 12 sub-watersheds. Based on the assumption, the main factors that enhance its relative water yield capacity include two aspects. The first one is the continuous increase 
of urban land and rural settlements in the Xiaguan Town and Dali town, which has almost doubled in 2008 from 1988. According to Equation (3) and Table 2, construction land has the lowest Kc value, which would lead to lower levels of actual evapotranspiration than other land use in the same condition. The other one is the implementation of the policy for grassland restoration from croplands and forests. There is a marked difference for the net water yield among the vegetation types [23,24]. For the different ET values, the grassland produces a higher water yield, the shrub forest provides a lower one, and the forest obtains the least one [23]. Consequently, units which have applied the grassland restoration policy will obtain a higher relative capacity.

The fluctuation pattern means the increasing interval and the decreasing interval occurs simultaneously and is adjacent. Furthermore, the unit changes in both of them are over 5 . This pattern was found in 16, 7, 18, 23, 26, 30, 33 and 10 sub-watersheds. Most of them are located in the southeast of Dali County, especially in the staggered zone of Wood Land, Grassland and Dry Land. The relative water yield capacity is affected by the implementation of the policy on agricultural structure adjustments and ecological construction. Restoring grassland from forest is beneficial to improving the relative water yield capacity [24]. While, restoring forest from cropland and pasture would lead to a decrease of the relative water yield capacity. In the staggered zone, where the geographical environment is relatively complicated, the land use change is somewhat frequent. As a result, the actual evapotranspiration varies obviously, and the fluctuation in water yield would be observed. In the unit whose subws_id $=10$, the substantial change is caused by the interannual variability of water level.

\subsection{Sensitivity of Water Yield to Precipitation}

To verify the sensitivity of the water yield to the precipitation in different parts of the study area, elasticity index of water yield and precipitation are introduced to describe the relationship between their dynamic changes. The index is defined as

$$
\eta_{\mathrm{i}}=\frac{\mathrm{u}_{\mathrm{wy}}}{\mathrm{u}_{\mathrm{p}}}=\frac{\left(W Y_{\mathrm{t}}-W Y_{\mathrm{t} 0}\right) / W Y_{\mathrm{t} 0}}{\left(\mathrm{P}_{\mathrm{t}}-\mathrm{P}_{\mathrm{t} 0}\right) / \mathrm{P}_{\mathrm{t} 0}}
$$

where, $\eta_{\mathrm{i}}$ is the elasticity index of water yield and precipitation in the $i^{\text {th }}$ interval $(i=1,2,3,4), \mathrm{WY}_{\mathrm{t}}$ and $\mathrm{WY}_{\mathrm{t} 0}$ are the water yield in the year $\mathrm{t}$ and $\mathrm{t}_{0}, \mathrm{P}_{\mathrm{t}}$ and $\mathrm{P}_{\mathrm{t} 0}$ are the precipitation in the year $\mathrm{t}$ and $\mathrm{t}_{0}, \mathrm{u}_{\mathrm{wy}}$ and $u_{p}$ are the growth rate of water yield and precipitation.

For example, $\eta_{1}$ is the elasticity index of water yield and precipitation during 1988-1995, $\mathrm{WY}_{\mathrm{t}}$ and $\mathrm{WY}_{\mathrm{t} 0}$ is the water yield in the year 1995 and 1988, and other parameters so on. Then, the average of elasticity coefficient in four intervals is taken to characterize the sensitivity of sub-watershed unit to the dynamic change of precipitation.

It is classified according to five categories by the natural breaks (Jenks) based on ArcGIS, which is presented in Figure 5. The classified statistical features are calculated, and are shown in Table 5. There is only one sub-watershed whose elasticity index is different with others. Its subws_id is 10. In 1988, 2000 and 2008, the water yield of this unit was almost zero, thus the elastic coefficient has an unbelievable value in the period of 1988-1995 and 2000-2005. As a result, it is labeled as infinity, which would not be analyzed in this paper. The sub-watersheds whose elasticity index is over 1.98 cover more than $95 \%$ of the total area. It indicates that water yield is sensitive to the change of the precipitation in the entire region, which can be delineated as an amplification effect. When rainfall 
increases, the water yield will grow to more than twice the rate of rainfall increase. As an example, the elasticity coefficient of unit 28 is 3.38 , which means its water yield will increase by $3.38 \%$ when the precipitation increases by $1 \%$. The greater the elasticity coefficient the more obvious is the amplification effect. The unit whose elasticity coefficient is the largest mainly located in Erhai and the paddy field in west of Erhai, and the following units are distributed in the staggered zone of Wood Land, Grassland and Dry Land in the south of Dali. The elasticity coefficient of the unit in these two areas is over 2.66. It indicates that the water yield would increase rapidly when the precipitation increases. In these areas, the probability of floods and the risk of mudslides, landslides and other natural disasters is higher than in other areas. Similarly, when the precipitation decreases, the water yield would decrease faster; this is not conducive to agriculture production. These regions which have a weaker resistance to natural disaster cover $52.41 \%$ of the entire area. This is important to consider when the extreme weather conditions are predicted.

The other regions whose elasticity coefficient is less than 2.66 are mainly distributed in the northwest, northeast and south of Dali. Compared to the above categories, these regions hold a stronger self-regulation capacity in precipitation changes. Combined with Figure $4 \mathrm{a}$, these regions are extremely similar to the Stable Category. To some extent, it proves the stability of water yield in these sub-watersheds.

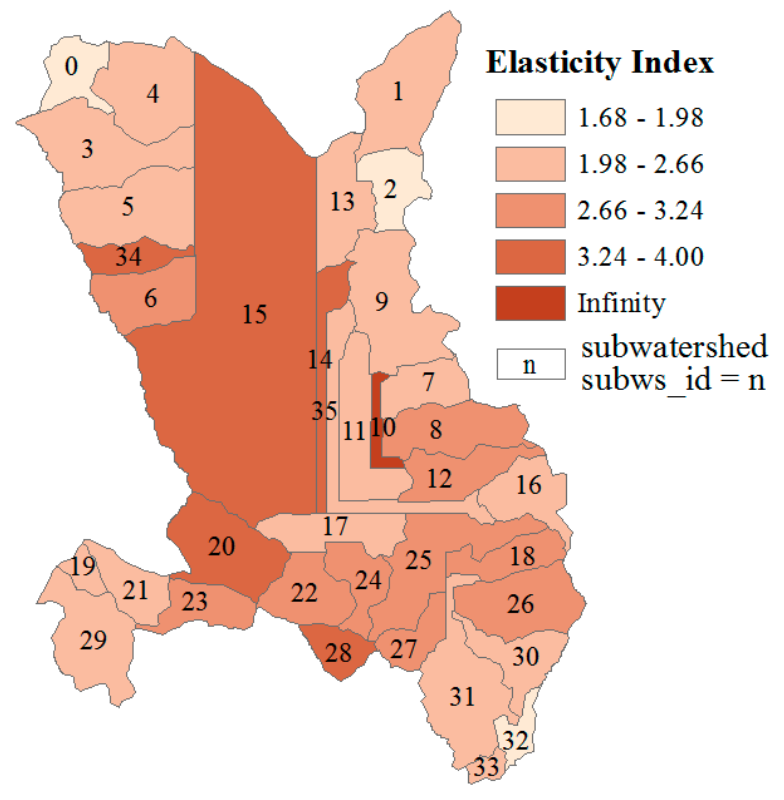

Figure 5. The average elasticity index of water yield and precipitation in sub-watershed scale.

Table 5. Classification statistical tables according to the elasticity index of water yield and precipitation.

\begin{tabular}{cccc}
\hline Elasticity Index & Number of Sub-Watershed & Area $\left(\mathbf{k m}^{\mathbf{2}}\right)$ & Ratio (\%) \\
\hline $1.68-1.98$ & 3 & 60 & 4.24 \\
$1.98-2.66$ & 17 & 612 & 43.28 \\
$2.66-3.24$ & 10 & 310 & 21.93 \\
$3.24-4.00$ & 5 & 431 & 30.48 \\
Infinity & 1 & 1 & 0.07 \\
\hline Sum & 36 & 1414 & 100 \\
\hline
\end{tabular}




\section{Conclusions}

The spatial and temporal variability of water yield is exceedingly significant. In the temporal dimension, the water yield experienced a fluctuating trend with a similar waveform to precipitation. In the spatial dimension, the majority of the units, which covered more than $90 \%$ of the area, belong to the Stable Category and Mild Interference Category. This means that the change of the geographical environment has little effect on the entire area. Sub-watersheds which have higher water yield are mainly located in the area where the elevation is high and both the elevation and the slope changes are large. The main land use includes Shrub Land, High Coverage Grassland, Wood Land and Dry Land. While, the sub-watersheds sorted in 2-5 are mainly distributed in the eastern part of Erhai or the surrounding area. The rest of the units which belong to the Stable Category are mainly distributed in the south of Dali.

There are three main factors that contributed to the change of water yield from 1988-2008 in Dali. The most important factor affecting water yield is still rainfall. The second is construction land expansion coinciding with urbanization. The third is the implementation of the policy on agricultural structure adjustment and ecological protection. In the staggered zones of Wood Land, Grassland and Dry Land, the geographical environment is relatively complicated, and the land use changes are somewhat frequent. As a result, a fluctuation in water yield should be observed.

An elasticity index of water yield and precipitation is introduced to describe the sensitivity of the water yield to precipitation. The sub-watersheds whose elasticity index is over 1.98 cover more than $95 \%$ of the total area. It indicates that water yield is sensitive to changes in precipitation in the entire region. The larger the elasticity index, the poorer the ability to resist natural disaster, while there is also a higher probability of flood or drought in these areas. Similarly, the risk of mudslides, landslides and other natural disasters are likewise higher. Thus, these findings can also provide a reference point for ecological risk.

\section{Acknowledgments}

This research was supported by China National Natural Science Funds for Distinguished Young Scholar (Grant No.71225005), the National Department Public Benefit Research Foundation of the Ministry of Land and Resources of China (Grant No. 201311001-5) and Hubei Provincial Natural Science Funds (No. 2014CFB545). Data support from Institute of Geographic Sciences and Natural Resources Research is greatly appreciated.

\section{Author Contributions}

Jing $\mathrm{Yu}$ developed the concept and wrote the text. Yongwei Yuan prepared the data. Yan Nie explored the method of parameters. Enjun Ma, Hongji Li and XiaoliGeng analyzed the data and drew the maps.

\section{Conflicts of Interest}

The authors declare no conflict of interest. 


\section{References and Notes}

1. Burkhard, B.; Kroll, F.; Nedkov, S.; Müller, F. Mapping ecosystem service supply, demand and budgets. Ecol. Indic. 2012, 21, 17-29.

2. Hoyer, R.; Chang, H. Assessment of freshwater ecosystem services in the Tualatin and Yamhill basins under climate change and urbanization. Appl. Geogr. 2014, 53, 402-416.

3. Ullrich, A.; Volk, M. Application of the Soil and Water Assessment Tool (SWAT) to predict the impact of alternative management practices on water quality and quantity. Agric. Water Manag. 2009, 96, 1207-1217.

4. Baker, T.J.; Scott, N.M. Using the Soil and Water Assessment Tool (SWAT) to assess land use impact on water resources in an East African watershed. J. Hydrol. 2013, 486, 100-111.

5. Kang, K.; Merwade, V. Development and application of a storage-release based distributed hydrologic model using GIS. J. Hydrol. 2011, 403, 1-13.

6. Refsgaard, J.C.; Auken, E.; Bamberg, C.A.; Christensen, B.S.; Clausen, T.; Dalgaard, E.; Effersø, F.; Ernstsen, V.; Gertz, F.; Hansen, A.L.; et al. Nitrate reduction in geologically heterogeneous catchments-A framework for assessing the scale of predictive capability of hydrological models. Sci. Total Environ. 2014, 468-469, 1278-1288.

7. De Lange, W.J.; Prinsen, G.F.; Hoogewoud, J.C.; Veldhuizen, A.A.; Verkaik, J.; Oude Essink, G.H.P.; van Walsum, P.E.V.; Delsman, J.R.; Hunink, J.C.; Massop, H.T.L.; et al. An operational, multi-scale, multi-model system for consensus-based, integrated water management and policy analysis: The Netherlands Hydrological Instrument. Environ. Model. Softw. 2014, 59, 98-108.

8. Abbott, M.B.; Bathurst, J.C.; Cunge, J.A.; O’Connell, P.E.; Rasmussen, J. An introduction to the European Hydrological System-Systeme Hydrologique Europeen, "SHE", 1: History and philosophy of a physically-based, distributed modelling system. J. Hydrol. 1986, 87, 45-59.

9. Singh, A.; Imtiyaz, M.; Isaac, R.K.; Denis, D.M. Comparison of soil and water assessment tool (SWAT) and multilayer perceptron (MLP) artificial neural network for predicting sediment yield in the Nagwa agricultural watershed in Jharkhand, India. Agric. Water Manag. 2012, 104, 113-120.

10. Zhang, C.; Li, W.; Zhang, B.; Liu, M. Water yield of Xitiaoxi river basin based on inVEST modeling. J. Resour. Ecol. 2012, 3, 50-54.

11. Sánchez-Canales, M.; López Benito, A.; Passuello, A.; Terrado, M.; Ziv, G.; Acuña, V.; Schuhmacher, M.; Elorza, F.J. Sensitivity analysis of ecosystem service valuation in a Mediterranean watershed. Sci. Total Environ. 2012, 440, 140-153.

12. Su, C.; Fu, B. Evolution of ecosystem services in the Chinese Loess Plateau under climatic and land use changes. Glob. Planet. Change 2013, 101, 119-128.

13. Chiang, L.-C.; Lin, Y.-P.; Huang, T.; Schmeller, D.S.; Verburg, P.H.; Liu, Y.-L.; Ding, T.-S. Simulation of ecosystem service responses to multiple disturbances from an earthquake and several typhoons. Landsc. Urban Plan. 2014, 122, 41-55.

14. Yunnan Environmental Protection Department, Regionalization of Ecological Environmental Function of Yunnan Province, Editor 2009. (In Chinese)

15. Water yield: Reservoir hydropower production. Available online: http://ncp-dev.stanford.edu/ $\sim$ dataportal/invest-releases/documentation/current_release/reservoirhydropowerproduction.html (accessed on 22 April 2015). 
16. Allen, R.G.; Pereira, L.S.; Raes, D.; Smith, M. Crop Evapotranspiration-Guidelines for Computing Crop Water Requirements-FAO Irrigation And Drainage Paper 56; Food and Agriculture Organization of the United Nations: Rome, Italy, 1998.

17. Dong, S.; Cui, H. Analysis of calculationg formula and improvement of empirical formula for saturation vapour pressure. J. Appl. Meteorol. Sci. 1992, 3, 501-508. (In Chinese)

18. Deng, X.; Jiang, Q.; Zhan, J.; He, S.; Lin, Y. Simulation on the dynamics of forest area changes in Northeast China. J. Geogr. Sci. 2010, 20, 495-509.

19. Boer, E.P.J.; de Beurs, K.; Hardkamp, A.D. A Dewi Hartkamp, Kriging and thin plate splines for mapping climate variables. Int. J. Appl. Earth Observ. Geoinf. 2001, 3, 146-154.

20. Wu, Q.; Wang, Z.; Cui Y. Evaluating the solar radiation resources of China in recent 20 years by meteorological model. J. Appl. Meteorol. Sci. 2010, 21, 343-351.

21. FAO/IIASA/ISRIC/ISSCAS/JRC. Harmonized World Soil Database v 1.2; FAO: Rome, Italy; IIASA: Laxenburg, Austria, 2012.

22. Liu, J.; Zhang, Z.; Zhuang, D.; Wang, Y.; Zhou, W.; Zhang, S.; Li, R.; Jiang, N.; Wu, S. A study on the spatial-temporal dynamic changes of land-useand driving forces analyses of China in the 1990s. Geogr. Res. 2003, 22, 1-12.

23. Wang, Y.; Yu, P.; Xiong, W.; Shen, Z.; Guo, M.; Shi, Z.; Du, A.; Wang, L. Water-yield reduction after afforestation and related processes in the semiarid liupan mountains, Northwest China. JAWRA J. Am. Water Resour. Assoc. 2008, 44, 1086-1097.

24. Salmoral, G.; Willaarts, B.A.; Troch, P.A.; Garridio, A. Drivers influencing streamflow changes in the Upper Turia basin, Spain. Sci. Total Environ. 2015, 503-504, 258-268.

(C) 2015 by the authors; licensee MDPI, Basel, Switzerland. This article is an open access article distributed under the terms and conditions of the Creative Commons Attribution license (http://creativecommons.org/licenses/by/4.0/). 